\title{
Indirect effects of oral tolerance to ovalbumin interfere with the immune responses triggered by Schistosoma mansoni eggs
}

C.R. Carvalho ${ }^{1}$, H.L. Lenzi ${ }^{3}$,

R. Correa-Oliveira 4 and N.M. Vaz ${ }^{2}$
Departamentos de ${ }^{1}$ M orfologia and ${ }^{2 B i o q u i ́ m i c a ~ e ~ I m u n o l o g i a, ~}$ Instituto de Ciências Biológicas, Universidade Federal de Minas Gerais, Belo Horizonte, M G, Brasil

${ }^{3}$ Departamento de Patologia, Instituto O swaldo Cruz, FIOCRUZ,

Rio de Janeiro, RJ, Brasil

${ }^{4}$ Centro de Pesquisas René Rachou, FIO CRUZ, Belo Horizonte, MG, Brasil

\section{Correspondence \\ C.R. Carvalho \\ Departamento de Morfologia \\ ICB, UFMG \\ Av. Antônio Carlos, 6627 \\ 31270-901 Belo Horizonte, MG \\ Brasil \\ E-mail: crochac@mono.icb.ufmg.br}

Presented at the XVII Annual Meeting of the Federação de Sociedades de Biologia Experimental, Salvador, BA, Brazil, August 28-31, 2002.

Research supported by FAPEMIG (No. CBS 2394/97) and CNPq (No. 520834/96-8).

Received April 18, 2002 Accepted August 6, 2002

\section{Abstract}

The objective of the present study was to investigate whether the injection of a tolerated protein (indirect effects) affects the formation of granulomas around Schistosoma mansoni eggs trapped in the lungs after intravenous (iv) injection into normal (noninfected) C57BL/6 mice (6 animals per group). To induce oral tolerance to chicken egg ovalbumin a $1 / 5$ dilution of egg white in water was offered ad libitum in a drinking bottle for 3 days. Control mice received water. After 7 days, control and experimental animals were injected $i v$ with 2,000 $S$. mansoni eggs through a tail vein. In some mice of both groups the $i v$ injection of eggs was immediately followed by intraperitoneal (ip) immunization with $10 \mu \mathrm{g}$ of dinitrophenylated conjugates of ovalbumin (DNP-Ova) emulsified in complete Freund's adjuvant (CFA) or only CFA; 18 days later, mice were bled and killed by ether inhalation. The lungs were fixed in formalin and embedded in paraffin. Serial sections of $5 \mu \mathrm{m}$ were stained with Giemsa, Gomori's silver reticulin and Sirius red ( $\mathrm{pH}$ 10.2). Granuloma diameters were measured in histological sections previously stained with Gomori's reticulin. AntiDNP and anti-soluble egg antigen (SEA) antibodies were analyzed by ELISA. In mice orally tolerant to ovalbumin the concomitant ip injection of DNP-Ova resulted in significantly lower anti-SEA antibodies (ELISA*: $1395 \pm 352$ in non-tolerant and $462 \pm 146$ in tolerant mice) and affected granuloma formation around eggs, significantly decreasing granuloma size (area: $22,260 \pm 2478$ to $12,993 \pm 3242$ $\mu \mathrm{m}^{2}$ ). Active mechanisms triggered by injection of tolerated antigen (ovalbumin) reduce granuloma formation.
Key words - Oral tolerance - Ovalbumin

- Granuloma

- Schistosoma mansoni 
The immune response to parasite eggs in host tissues significantly affects the disease resulting from infection with Schistosoma mansoni. Granulomatous lesions lead to fibrosis, which in turn can produce severe circulatory impairment of the affected organs (1). Granulomas enclosing eggs arise through a process dependent on sensitized CD4+ T lymphocytes (2), and the granulomas forming around newly deposited eggs, which are larger during the early acute phase of infection, become smaller during the late chronic phase of the disease (3). This regression in pathology has been attributed to modulation due to immunoregulatory events affecting $\mathrm{T}$ cell responses to egg antigens, which also declines during this period $(4,5)$.

Oral tolerance, a major example of immunoregulation, is defined as a reduction in specific immune responsiveness after immunization with an antigen previously administered by the oral route (6). Oral tolerance, which has direct effects on the specific responsiveness to the tolerated proteins, has also indirect effects on responsiveness to other, unrelated immunogens injected concomitantly with the tolerated proteins (7-9). The indirect effects of antigen re-exposure in orally tolerant mice block severe chronic inflammatory reactions of immunological origin, such as autoimmune reactions and graft-versus-host reactions $(10,11)$.

Viable eggs from $S$. mansoni injected intravenously (iv) may be trapped in the small arteries of the lung. Subsequent immune responses to immunogenic products secreted by the eggs (soluble egg antigens, SEA) result in the formation of pulmonary granulomas. The present experiments were undertaken to determine whether the injection of chicken egg ovalbumin (Ova) into mice previously rendered orally tolerant to egg white proteins would affect the development of granulomas around S. mansoni eggs trapped in the lungs after $i v$ injection. The results showed that indeed a significant re- duction in granuloma formation occurs.

Eight-week-old C57BL/6 mice were used (6 animals per group). To induce oral tolerance an egg white solution (1/5 dilution in water) was offered ad libitum in a drinking bottle for 3 consecutive days as the only source of liquid. Control mice received water. After 7 days, control and experimental animals were injected $i v$ with 2,000 eggs from $S$. mansoni through a tail vein. In some mice of both groups the $i v$ injection of eggs was immediately followed by intraperitoneal (ip) immunization with $10 \mu \mathrm{g}$ of dinitrophenylated conjugates of Ova (DNP-Ova) emulsified in complete Freund's adjuvant (CFA) or only CFA. DNP-Ova conjugates were prepared by coupling with dinitrophenyl sulfonate as described by Ovary and Benacerraf (12).

Eighteen days after $i v$ injection of eggs the mice were anesthetized by ether inhalation, bled and immediately sacrificed by inhalation of an ether overdose. The serum was collected and frozen for later analysis of antibodies. The lungs were removed, fixed in Carson's modified Millonig's phosphate-

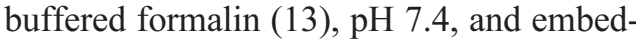
ded in paraffin. Serial sections of $5 \mu \mathrm{m}$ were stained by the following methods for bright field microscopy: hematoxylin and eosin and Lennert's Giemsa for cellular characterization, and Gomori's silver reticulin for identification of collagen-containing reticular fibers. For confocal laser scanning microscopy the sections were stained with Sirius red $(\mathrm{pH}$ 10.2) for identification of eosinophils and phosphomolybdic acid-picrosirius red for collagen, and analyzed by the reflected mode using a $543 \mathrm{~nm}$ laser (LSM 410, Zeiss, Oberkochen, Germany).

The diameters of pulmonary granulomas were measured in histological sections previously stained with Gomori's reticulin using the LSM 410 software. Only sections of granulomas with central egg(s) were considered.

Antibodies were assayed by standard 
ELISA procedures using high absorption plates (Nunc, Roskilde, Denmark) incubated overnight at $4^{\circ} \mathrm{C}$ with $2 \mu \mathrm{g}$ DNP-BSA or SEA per well. Absorbance at $492 \mathrm{~nm}$ was read in an ELISA reader (model 450 Microplate Reader, Bio-Rad Laboratories, Hercules, CA, USA). For each sample of serum, the absorbances of the eight serial dilutions were added and multiplied by 1000 and these coded values were called ELISA* (ELISA scores), as done in previous studies by our group $(14,15)$. These ELISA scores were used for statistical analysis using the unpaired $t$-test.

To confirm the establishment of oral tolerance the anti-DNP antibody response was measured 18 days after ip immunization with DNP-Ova in CFA and, in agreement with many previously published reports, the antiDNP antibody responses were significantly lower in mice orally pretreated with an egg white solution for 3 consecutive days before parenteral immunizations when compared to those not orally pretreated (data not shown).

The anti-SEA responses are shown in Figure 1A. The $i v$ injection of eggs in control mice without additional immunization resulted in high titers of anti-SEA antibodies. In non-tolerant mice, the concomitant ip injection of DNP-Ova did not interfere with this antibody response to SEA. In contrast, in mice rendered orally tolerant to Ova, the concomitant ip injection of DNP-Ova resulted in significantly lower anti-SEA antibody production. Curiously, injection of CFA alone in mice orally pretreated with Ova triggered a lower response to SEA, but this reduction was not statistically significant.

The indirect effects of DNP-Ova injection into Ova-tolerant mice also affected granuloma formation around eggs. As shown in Figure 1B, there was a significant reduction in granuloma size (area) in Ova-tolerant mice immunized $i p$ with DNP-Ova concomitantly with $i v$ injection of $S$. mansoni eggs, as compared to a control group only injected with eggs.

As described in the literature, the granuloma around $S$. mansoni eggs has a defined maturational stage followed by a stage of involution and from a morphological point of view these stages may be classified as pregranulomatous and granulomatous stages (16). The pre-granulomatous, exudative stage is characterized by accumulation of eosinophils and monocytes around the egg. The granulomatous stages can be divided into three phases: exudative-productive, productive and involutional.

In the present experiments, differences in the frequency of occurrence of the distinct phases in the various experimental groups were apparent. The more prominent granulomas emerged in non-tolerant mice concomitantly injected with DNP-Ova, which

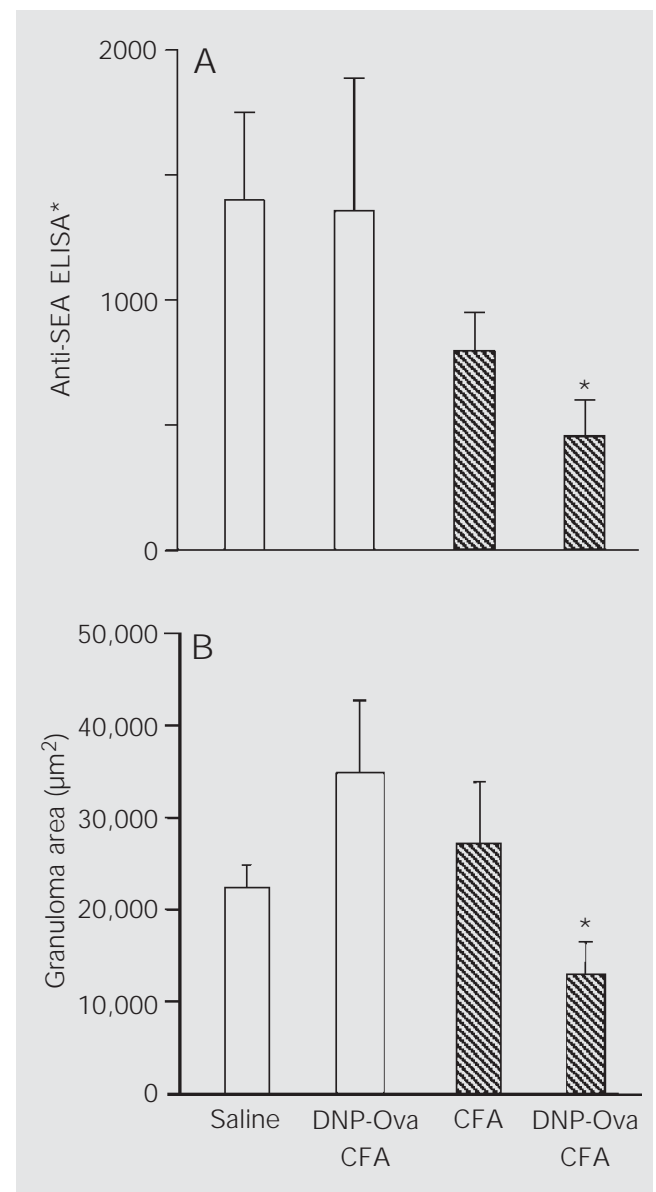

Figure 1. Effect of immunization with DNP-Ova plus CFA in Ovatolerant and non-tolerant mice on anti-SEA antibodies (A) and granuloma area (B). All mice were injected iv with Schistosoma mansoni eggs. Concomitant ip immunizations as described in the text were applied to nontolerant control (open bars) and Ova-tolerant (hatched bars) mice. See text for definition of ELISA*. DNP-Ova = dinitrophenylated ovalbumin, SEA = soluble egg antigen, CFA = complete Freund's adjuvant. $* \mathrm{P}<0.05$ compared to control (ip saline) mice (unpaired t-test). 
were exudative-productive granulomas. Also, mice in this group displayed exudative-productive granulomas with three layers: a cellular periovular layer with a small number of macrophages, an intermedial layer with concentric collagen fibers, and an external layer with collagen fibers arranged in a mesh including also monocytes and eosinophils (Figure $2 \mathrm{~A}, \mathrm{~B}$ ).

On the other hand, the highest proportions of small granulomas were found in orally tolerant mice injected with DNP-Ova. In this group there was a predominance of intravascular eggs with an initial periovular reaction containing monocytes, eosinophils and collagen fibers derived from the vascular wall (Figure 2C).

Despite the differences in granuloma
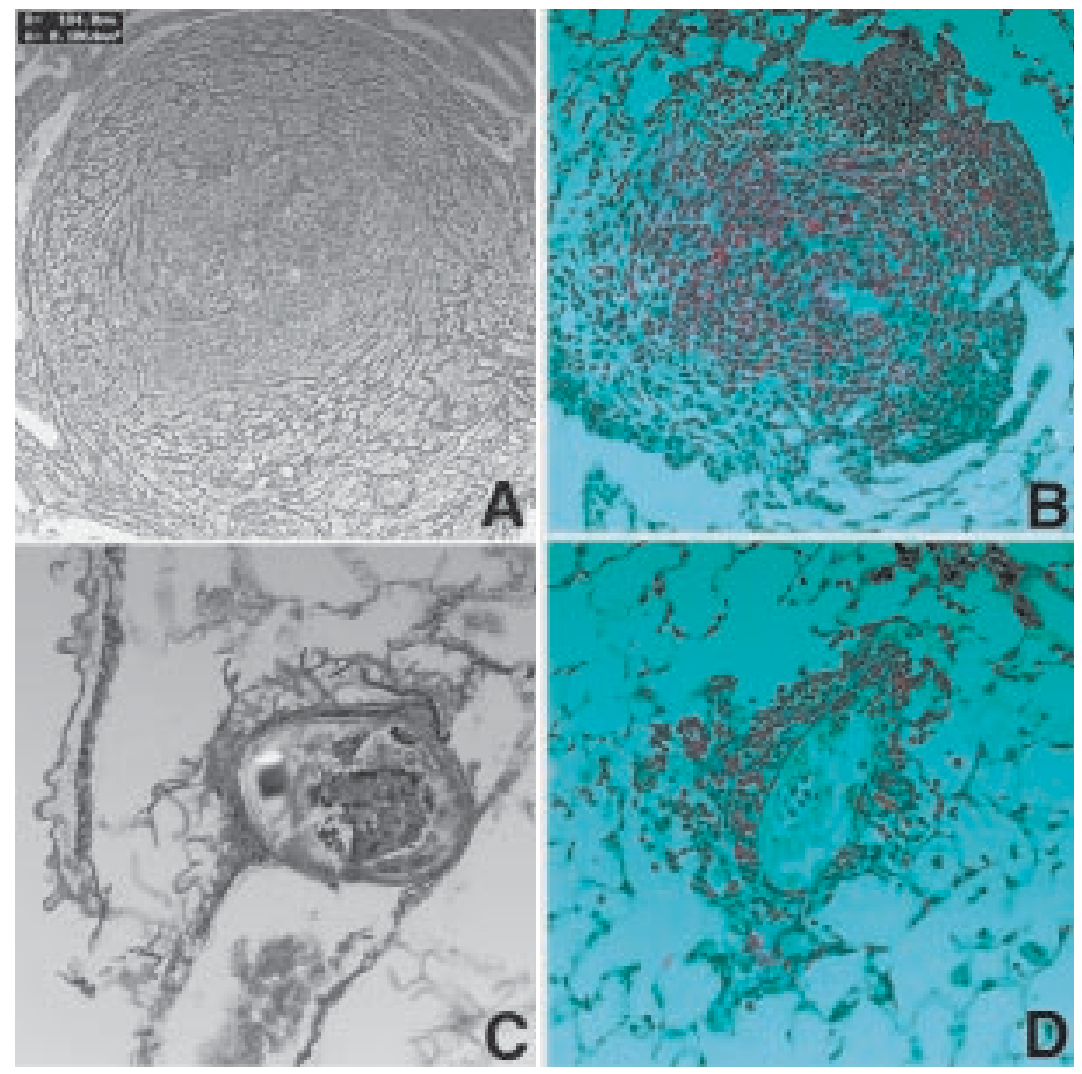

Figure 2. Granulomas from non-tolerant (A, B) and Ova-tolerant (C, D) mice injected ip with DNP-Ova concomitantly with iv injection of eggs. The sections were stained with Gomori's reticulin for identification of collagen-containing reticular fibers $(A, C)$ or Sirius red $(\mathrm{pH} 10.2)$ for identification of eosinophils in red (B, D). Original magnifications are 400X (A, B), 1000X (C) and 500X (D). areas, all groups presented a similar cellular composition with a predominance of macrophages and eosinophils. Eosinophils were present even in the smaller granulomas of the orally Ova-tolerant mice (Figure 2D).

The results outlined above show another example of the indirect effects of oral tolerance interfering with a chronic inflammatory reaction.

Specific immunological tolerance, previously identified as non-responsiveness and sometimes attributed to deletion (17) or anergy (18) of responsive clones, can be shown to be an active process, which has been attributed to the activity of subpopulations of CD4+ T lymphocytes bearing the CD25 marker $(6,19)$. In the experiments described here the active mechanisms triggered by injection of tolerated antigen affects indirectly granuloma formation. It has been suggested that the indirect effects of tolerated antigen injection are nonspecific and result from "innocent bystander suppression" by inhibitory cytokines specifically released in response to the tolerated protein $(10,20)$. There is evidence, however, that this may not be the case (14). For example, indirect effects do not require the simultaneous injection of the two proteins but, when the injections are separated in time, the tolerated protein has to be injected first. Indirect effects do not block secondary responses to unrelated proteins if the primary immunization is made in the absence of the tolerated protein. We suggest that indirect effects may be better understood in terms of systemic models $(8,14)$.

We speculate that injection of tolerated antigens has systemic immunological effects and the observed changes in chronic inflammatory reaction may be due to alterations in leukocyte migration to inflammatory sites. To determine whether this is the case we are currently evaluating the expression of adhesion molecules on leukocytes and endothelial cells after injection of tolerated antigen. 


\section{References}

1. Phillips SM \& Lammie PJ (1986). Immunopathology of granuloma formation and fibrosis in schistosomiasis. Parasitology Today, 2: 296-301.

2. Phillips SM, DiConza J J , Gold J A \& Reid WA (1977). Schistosomiasis in the congenitally athymic (nude) mouse. I. Thymic dependency of eosinophilia, granuloma formation, and host morbidity. J ournal of Immunology, 118: 594-599.

3. Domingo EO \& Warren KS (1968). Endogenous desensitization: changing host granulomatous response to schistosome eggs at different stages of infection with Schistosoma mansoni. American J ournal of Pathology, 52: 369-379.

4. Colley DG (1981). T lymphocytes that contribute to the immunoregulation of granuloma formation in chronic murine schistosomiasis. J ournal of Immunology, 126: 1465-1468.

5. Green WF \& Colley DG (1981). Modulation of Schistosoma mansoni egg-induced granuloma formation: I-J restriction of $\mathrm{T}$ cell-mediated suppression in a chronic parasitic infection. Proceedings of the $\mathrm{Na}-$ tional Academy of Sciences, USA, 78: 1152-1156.

6. Faria AM \& Weiner HL (1999). Oral tolerance: mechanisms and therapeutic applications. Advances in Immunology, 73: 153-264.

7. Vaz NM, Hanson DG, Maia LCS \& Lynch J L (1981). Cross-suppression of specific immune responses after oral tolerance. Memórias do Instituto Oswaldo Cruz, 76: 83-91.

8. Carvalho CR, Verdolin BA, de Souza AV \& Vaz NM (1994). Indirect effects of oral tolerance in mice. Scandinavian J oumal of Immunology, 39: 533-538.

9. Carvalho CR \& Vaz NM (1996). Indirect effects are independent of the way of tolerance induction. Scandinavian J ournal of Immunology, 43: 613-618.

10. Miller A, Lider O \& Weiner HL (1991). Antigen driven bystander suppression after oral administration of antigen. J ournal of Experimental Medicine, 174: 791-798.

11. Vaz NM \& Carvalho CR (1994). Assimilation, tolerance and the end of innocence. Ciência e Cultura, 46: 351-357.

12. Ovary $Z \&$ Benacerraf B (1963). Immunological specificity of the secondary response with dinitrophenylated proteins. Proceedings of the Society for Experimental Biology and Medicine, 124: 72-76.

13. Carson F, Martin J \& Lynn J (1973). Formalin fixation for electron microscopy: A re-evaluation. American J ournal of Clinical Pathology, 59: 365-373.

14. Carvalho $C R$, Verdolin BA \& Vaz NM (1997). Indirect effects of oral tolerance cannot be ascribed to bystander suppression. Scandinavian J ournal of Immunology, 45: 276-281.

15. Verdolin BA, Ficker SM, Faria AM, Vaz NM \& Carvalho CR (2001). Stabilization of serum antibody responses triggered by initial mucosal contact with the antigen independently of oral tolerance induction. Brazilian J ournal of Medical and Biological Research, 34: 211-219.

16. Lenzi $H L$, Kimmel $E$, Schechtman $H$, Pelajo-Machado M, Romanha WS, Pacheco RG, Mariano M \& Lenzi J A (1998). Histoarchitecture of schistosomal granuloma development and involution: morphogenetic and biomechanical approaches. Memórias do Instituto Oswaldo Cruz, 93 (Suppl 1): 141-151.

17. Chen Y, Inobe JI, Marks R, Gonella P, Kuchroo VK \& Weiner HL (1995). Peripheral deletion of antigen-reactive T cells in oral tolerance. Nature, 376: 177-180.

18. Melamed D \& Friedman A (1993). Direct evidence for anergy in $T$ lymphocytes tolerized by oral administration of ovalbumin. European J ournal of Immunology, 23: 935-942.

19. Thorstenson KM \& Khoruts A (2001). Generation of anergic and potentially immunoregulatory $\mathrm{CD} 25+\mathrm{CD} 4 \mathrm{~T}$ cells in vivo after induction of peripheral tolerance with intravenous or oral antigen. J ournal of Immunology, 167: 188-195.

20. Teng YT, Gorczynski RM \& Hozumi N (1998). The function of TGF-beta-mediated innocent bystander suppression associated with physiological self-tolerance in vivo. Cellular Immunology, 190: 56-60. 